Research Article

\title{
Fuzzy-Sliding Mode Force Control Research on Robotic Machining
}

\author{
Shou-yan Chen, Tie Zhang, and Yan-biao Zou \\ School of Mechanical and Automotive Engineering, South China University of Technology, Guangzhou, Guangdong 510640, China \\ Correspondence should be addressed to Tie Zhang; merobot@scut.edu.cn
}

Received 10 January 2017; Revised 18 April 2017; Accepted 23 April 2017; Published 18 May 2017

Academic Editor: Keigo Watanabe

Copyright (C) 2017 Shou-yan Chen et al. This is an open access article distributed under the Creative Commons Attribution License, which permits unrestricted use, distribution, and reproduction in any medium, provided the original work is properly cited.

\begin{abstract}
The low stiffness has limited the applications of robot to machining process. In this paper, a fuzzy-sliding mode control scheme is proposed to manage the oscillation and chatter appearing in machining operation by adjusting the feed rate. The robotic machining dynamics is first analyzed to identify the parameters with focus on the system stiffness and the behavior during machining process. A controller consisting of a fuzzy estimation enginery which can determine the control gain coefficients according to system status and a sliding mode controller which is used to guarantee convergence and global stability of the system is then proposed. Simulations and experiments results show that, in comparison with open loop and fuzzy-PID control scheme, the fuzzy-sliding mode control scheme can reduce the amplitude and period of oscillation.
\end{abstract}

\section{Introduction}

Industrial robot is now worldwide applied in many fields such as material transfer, machining, and assembling [1-3]. As for machining, many studies have been reported and the results indicated that some critical issues, including trajectory error, material removal rate, and contacting force, are needed to be addressed.

To identify the relationship between removal rate and contacting force, Domroes and Krewet [4] compared the performance of force dependent feed rate control and orthogonal force control and reached a conclusion that the removal rate at constant force varies around a mean value. This statement is also agreed upon by Karayiannidis and Doulgeri [5], who proposed an adaptive leaning controller to identify the surface condition with the use of force and joint position/velocity measurements. The results show that the controller can reduce the distortion and tracking error caused by frictional contacts and uncertainties on the contacted surface. For unknown object and environment, Kiguchi and Fukuda [6] proposed an intelligent controller which was constructed on the basis of adaptive fuzzy neural position/force strategy, while Žarko and Vlastimir [7] proposed adaptive neurofuzzy-genetic control schemes for explicit force robot control.
However, the negative effects on machining performance, caused by the low stiffness of robot, have not been discussed in these studies.

The influence of the low stiffness of robot on machining has been noticed by Matsuoka et al. [8] since 1996, who studied the characteristics of robotic milling operation and proposed a method to reduce the effect caused by low stiffness. To further explore the influence of low stiffness on machining error, Abele et al. [9] identified the robot stiffness by two methods and conducted machining experiments whose results indicated that the path displacement, caused by robot low stiffness, plays a significant role in robotic machining error. With a view of this, many researchers have proposed some measures to compensate for the deformation. Zhang et al. [10] analyzed the coupling relationship between the joint rigidity and Cartesian rigidity and established an online compensation model. Wang et al. [11] present a compensation scheme based on joint stiffness model to reduce the machining deformation caused by machining force.

This paper presents a fuzzy-sliding mode control scheme to compensate for the deformation and oscillation caused by machining force. The robotic machining dynamics is first 


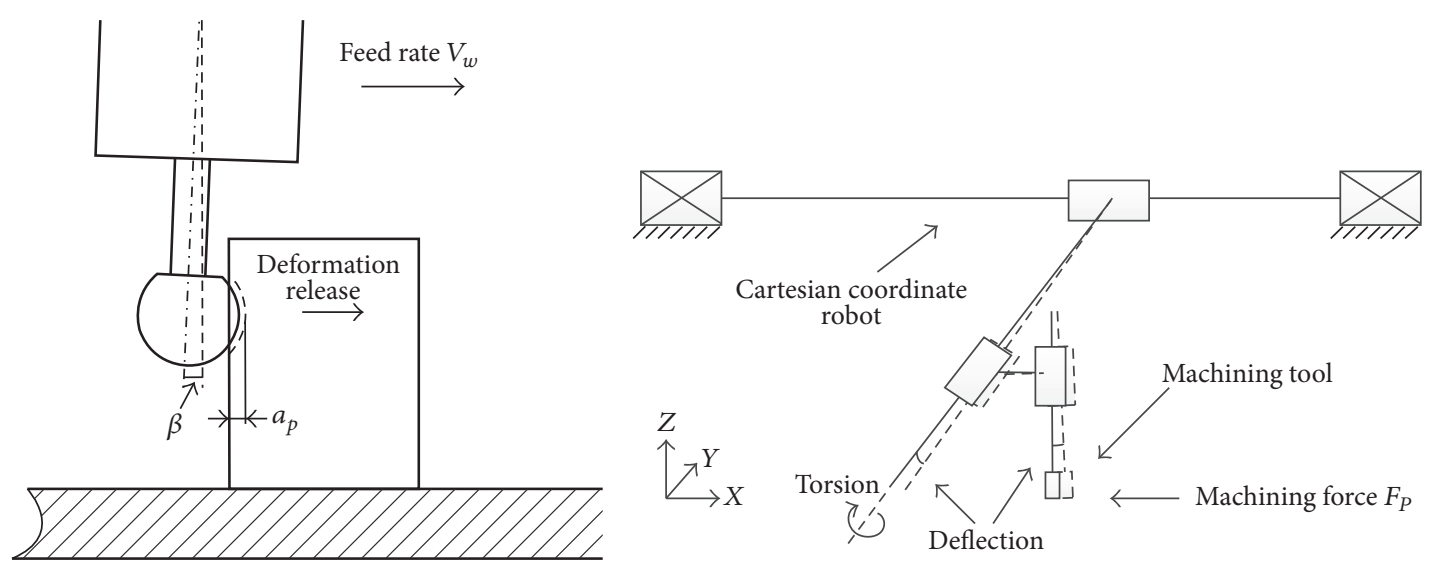

Figure 1: Generation of cutting deformation.

analyzed to identify the parameters with focus on the system stiffness and its behavior during machining process. With the knowledge of machining behavior, a sliding mode controller is then constructed based on fuzzy rules to manage the complexity of robotic machining. Simulations and experiments are subsequently conducted to evaluate the performance of the control scheme.

\section{Cutting Dynamics}

Compared with CNC, the stiffness of robotic is lower, which may result in larger path deviation and oscillation during machining process. Before establishing the dynamics model of robotic machining, the formation of deformation is illustrated.

2.1. Robotic Deformation. As shown in Figure 1, the rotating tool moves towards the workpiece at a feed rate $V_{w}$ and extrudes the workpiece to perform machining. When machining force is applied to the machining tool, deflections and torsion on robotic system occur and result in a position offset on end-effector. To facilitate the following discussion, this position offset is regarded as a deflection on end-effector and the deflection results in an unmachined area $\sigma_{t}=$ $\left[\sigma_{x}, \sigma_{y}, \sigma_{z}\right]^{\mathrm{T}}$ (labeled as deformation in the following discussion). The deflection is gradually released as the machining continues.

The generation and release process of deflection can be observed in Figure 2. The cutting force reaches the peak value at $10 \mathrm{~N}$ when the encoder displays that the robot reaches the required depth. However, the machining force does not go back to $0 \mathrm{~N}$ immediately and performs a sustained oscillation, decreasing from around $3 \mathrm{~N}$ to $1 \mathrm{~N}$, which indicates that the machining operation is still conducting. Therefore, it can be deduced that a deformation $\sigma_{t}$ occurs in machining process which can lead to a deviation between actual path and planned path as shown in Figure 3. The deformation $\sigma_{t}$ can be considered as the integration of speed difference

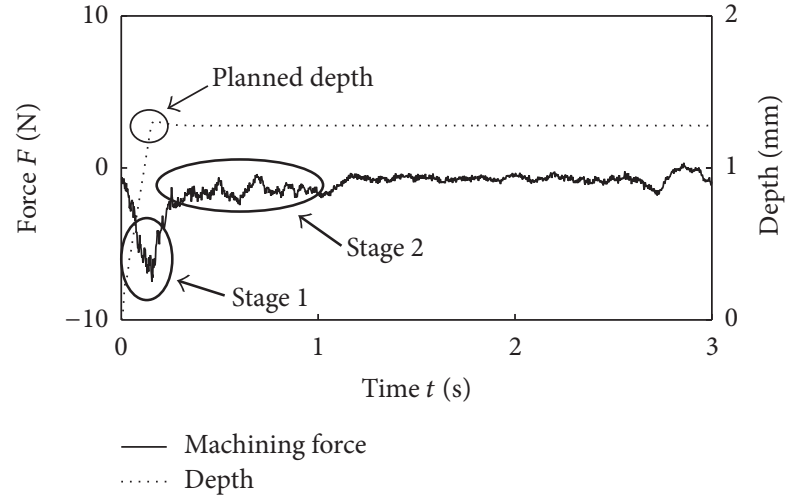

Figure 2: Deformation release process.

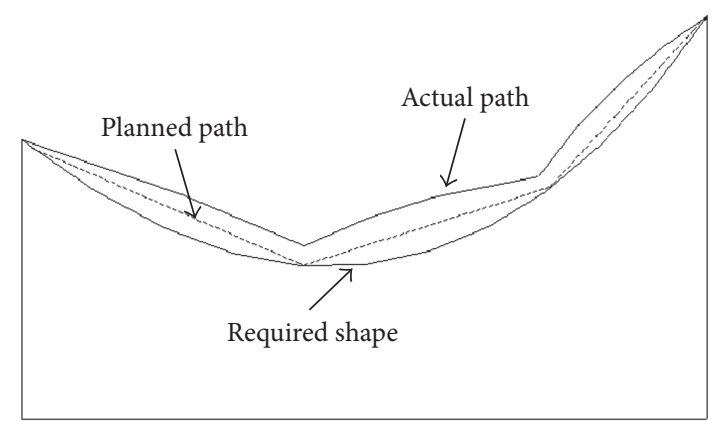

FIGURE 3: Deviation between planned path and actual path.

$V_{c}(t)$ between feed rate $V_{w}$ and removal rate $V_{e}$, which can be expressed as

$$
\sigma_{t}=\sum V_{c}\left(t_{i}\right) t=\sum\left(V_{w}\left(t_{i}\right)-V_{e}\left(t_{i}\right)\right) t
$$

As shown in Figure 2, an oscillation of force appears at stage 2 . This is due to the release of deformation which occurs 
when $V_{w}\left(t_{i}\right) \leq V_{e}\left(t_{i}\right)$. The oscillation force can be expressed as

$$
\begin{gathered}
F_{o}\left(t_{i}\right)=K_{s} \sigma_{t}\left(t_{i-1}\right) * \sin (w t+\varphi) \\
\sigma_{t}\left(t_{i-1}\right)=\sigma_{t}\left(t_{i}\right)-\left(V_{e}\left(t_{i}\right)-V_{w}\left(t_{i}\right)\right) t,
\end{gathered}
$$

where $F_{o}\left(t_{i}\right)$ is the force caused by the deformation release; $w$ and $\varphi$ are the robotic system coefficients. Therefore, the force caused by deformation can be expressed as

$$
\begin{aligned}
F_{s} & \left(t_{i}\right) \\
& = \begin{cases}K_{s} \sigma_{t}\left(t_{i-1}\right) & V_{w}\left(t_{i}\right) \geq V_{e}\left(t_{i}\right) \\
K_{s} \sigma_{t}\left(t_{i-1}\right) * \sin (w t+\varphi) & V_{w}\left(t_{i}\right) \leq V_{e}\left(t_{i}\right) .\end{cases}
\end{aligned}
$$

Compared with stage 1 , the force at stage 2 is much smaller, while the feed rate decreases from $V_{w}$ to 0 . Based on this, an assumption can be made that the values of feed rate and deformation $\sigma_{t}$ have significant influences on the force acting on cutter.

2.2. Robotic Cutting Dynamics. General cutting dynamic model can be expressed as

$$
F_{p}\left(t_{i}\right)=M \ddot{X}_{p}\left(t_{i}\right)+C \dot{X}_{p}\left(t_{i}\right)+K_{p} X_{p}\left(t_{i}\right)
$$

Considering the influence of deformation, the dynamic model in Cartesian frame can be written as

$$
\begin{aligned}
F\left(t_{i}\right)= & F_{p}\left(t_{i}\right)+F_{s}\left(t_{i}\right) \\
F\left(t_{i}\right)= & M \ddot{X}_{p}\left(t_{i}\right)+C \dot{X}_{p}\left(t_{i}\right)+K_{p} X_{p}\left(t_{i}\right) \\
& +K_{s} \sigma_{t}\left(t_{i-1}\right),
\end{aligned}
$$

where $F=\left[F_{x}, F_{y}, F_{z}\right]$ represents the machining force, $f_{x}$ is the force perpendicular to the chamfer surface, and $f_{y}$ is the force tangential to the chamfer surface. Machining force consists of contact force in normal direction and friction force in tangent direction. Considering the fact that the machining quality in normal direction of workpiece is more important, this paper focuses on the control of machining deformation in normal direction. $F_{p}$ represents the cutting force; $F_{s}$ represent the force caused by deformation; $M$ is the mass coefficient; $C$ is the damping coefficient; $\sigma_{t}\left(t_{i-1}\right)$ is the deformation at time $t_{i-1} ; K_{p}$ is the process stiffness; $K_{s}$ is the static stiffness. According to preliminary experiment result, a preconclusion can be made that the value of $K_{s}$ is much larger than the one of $K_{p} . X_{p}\left(t_{i}\right), \dot{X}_{p}\left(t_{i}\right)$, and $\ddot{X}_{p}\left(t_{i}\right)$ are the position of machining tool and its first-order derivative and secondorder derivative, where $X_{p}=\left[x_{x}, x_{y}, x_{z}\right]^{\mathrm{T}}$ and $x_{x}$ is the cutting position perpendicular to the chamfer surface which is regarded as machining depth $x_{x}=a_{p} ; x_{y}$ is the cutting position tangential to the chamfer surface. Considering the fact that the desired machining depth is $a_{p}^{*}$, (5) can be rewritten as

$$
\begin{aligned}
& M \ddot{a}_{p}^{*}\left(t_{i}\right)+C \dot{a}_{p}^{*}\left(t_{i}\right)+K_{p} a_{p}^{*}\left(t_{i}\right)+K_{s} \sigma_{x}\left(t_{i-1}\right)=F_{\mathrm{x}} \\
& a_{p}^{*}\left(t_{i}\right)=a_{s p}^{*}\left(t_{i}\right)-\sigma_{x}\left(t_{i-1}\right) \\
& =a_{s p}^{*}\left(t_{i}\right)-\sum_{1}^{i-1}\left(V_{w x}\left(t_{j}\right)-V_{e x}\left(t_{j}\right)\right) t,
\end{aligned}
$$

where $V_{w x}$ and $V_{e x}$ are the feed rate and removal rate component perpendicular to the chamfer surface and can be calculated by

$$
\begin{aligned}
& V_{w x}=\left|V_{w}\right| \sin \theta \\
& V_{e x}=\left|V_{e}\right| \sin \theta
\end{aligned}
$$

and $\theta$ is the machining angle. Define the machining force error perpendicular to the chamfer surface as $e_{x}=F_{x}-$ $F_{x}^{\prime}$, while the machining depth error caused by robotic deformation is $e_{p}=\sigma_{x}(t)=a_{p}(t)-a_{p}^{*}(t)$. According to the coupling relationship illustrated in (7), the desired machining depth $a_{p}^{*}(t)$ and machining force $F_{x}^{\prime}$ can be achieved by the modifications of $\theta,\left|V_{w}\right|$, and $a_{s p}^{*}(t)$. The values of $\theta$ and $a_{s p}^{*}(t)$ in this research are constant sets and the focus of this paper is to adjust $\left|V_{w}\right|$ to reduce the force deviation $e_{x}$. An alternative solution to reduce deformation is to slow down feed rate $V_{w}$. The decrease of approaching velocity can lead to a decrease of machining efficiency. Since machining efficiency is one of the key elements needed to be considered, this paper aims to reduce initial overshoot and machining deformation on the premise that the machining efficiency is guaranteed.

\section{Fuzzy-Sliding Mode Control Scheme}

Define $V_{w}$ as the control output; then

$$
\dot{F}=f\left(F_{x}\right)+g\left(F_{x}\right) V_{w},
$$

where $g\left(F_{x}\right)$ is the gain coefficient of the control law; $f\left(F_{x}\right)$ is the uncertainties of robotic system. According to the analysis above, the machining force and deformation are affected by machining angle and feed rate. To deal with the complexity of machining force caused by the shift of machining angle, a sliding mode control scheme based on fuzzy rules is proposed in this part.

3.1. Sliding Mode Control Scheme for Machining Process. The advantage of sliding mode is to transform the $n$th order tracking problem into first-order stability problem. Define the sliding surface as

$$
S=\left(\frac{d}{d t}+\lambda\right) e_{x}\left(t_{i}\right)=0
$$

where $\lambda$ is a positive constant, and the control law is

$$
V_{w}=u=\dot{S}=-H_{k} S-H_{c} \operatorname{sgn}(S) .
$$




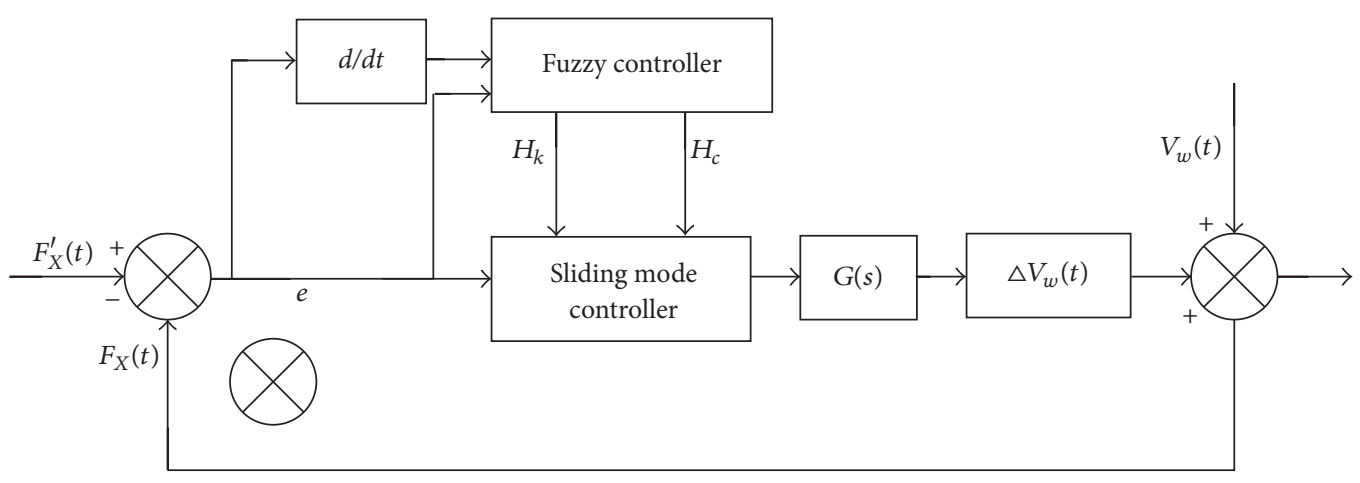

FIGURE 4: Fuzzy-sliding mode control scheme.

$H_{k}$ and $H_{c}$ are the gain coefficient of sliding mode control. When the system status achieves desired status within given precision $\varepsilon$ at time $t_{i}$, there are

$$
\begin{array}{r}
\left|e_{x}\left(t_{i}\right)\right| \leq \varepsilon, \\
S=0 .
\end{array}
$$

Equation (10) can be rewritten as

$$
\begin{aligned}
\lambda e_{x}\left(t_{i}\right)+\dot{e}_{x}\left(t_{i}\right) & =0 \\
\lambda e_{x}\left(t_{i}\right)+e_{x}\left(t_{i}\right)-e_{x}\left(t_{i-1}\right) & =0 \\
\left|e_{x}\left(t_{i-1}\right)\right| & \leq(\lambda+1) \varepsilon .
\end{aligned}
$$

Deduce

$$
\left|e_{x}\left(t_{i-n}\right)\right| \leq(\lambda+1)^{n} \varepsilon
$$

In the same way, we can get

$$
\begin{aligned}
& \left|-g\left(F_{x}\right) H_{c}\left(t_{i}\right) \operatorname{sgn}\left(S\left(t_{i}\right)\right)\right| \leq(\lambda+1) \varepsilon \\
& \left(-g\left(F_{x}\right) H_{k}\left(t_{i-n}\right) S\left(t_{i-n}\right)\right. \\
& \left.\quad-g\left(F_{x}\right) H_{c}\left(t_{i-n}\right) \operatorname{sgn}\left(S\left(t_{i-n}\right)\right)\right)^{n} \leq(\lambda+1)^{n+1} \varepsilon .
\end{aligned}
$$

Lyapunov is used to ensure the global stability:

$$
\begin{aligned}
& L_{p}=\frac{1}{2} S^{2} \\
& \dot{L}_{p}=\left(-H_{k} S-H_{c} \operatorname{sgn}(S)\right) S \leq 0 .
\end{aligned}
$$

Therefore, the gain coefficients $H_{c}$ and $H_{k}$ can be modified online during machining process when they are subject to (15) and (16).

3.2. Fuzzy-Sliding Mode Control Scheme. Fuzzy rules are used to determine the real-time value of $H_{c}$ and $H_{k}$ by evaluating the status of system. The inputs fuzzy variables are force deviation $e_{x}$ and its first-order derivative $\dot{e}_{x}$, and their domains are $e_{x}=\{-10,-5,0,5,10\}$ and $\dot{e}_{x}=\{-10,-5,0,5,10\}$. The domains of $H_{c}$ and $H_{k}$ are $H_{c}=\{-2,-1,0,1,2\}$ and $H_{k}=$

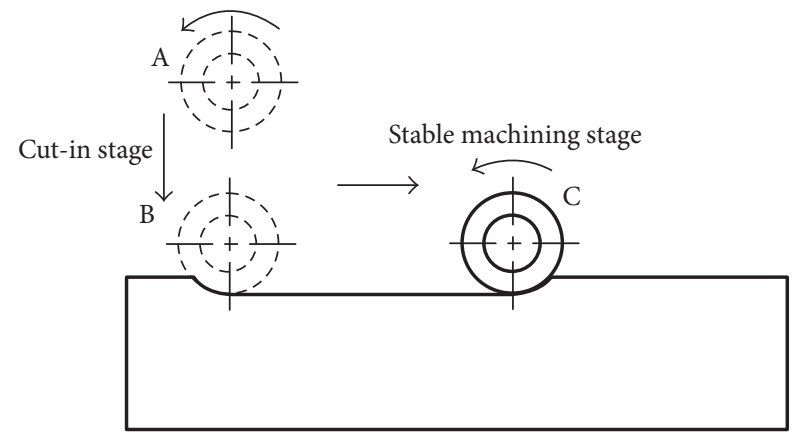

FIgURE 5: Machining path.

$\{-0.2,-0.1,0,0.1,0.2\}$. With use of Gaussian membership function and center of gravity method [12],

$$
\begin{aligned}
H_{c}\left(t_{i}\right) & =\frac{\sum_{1}^{l} H_{c i} \mu_{i}}{\sum_{1}^{l} \mu_{i}} \\
H_{k}\left(t_{i}\right) & =\frac{\sum_{1}^{l} H_{k i} \mu_{i}}{\sum_{1}^{l} \mu_{i}},
\end{aligned}
$$

where $i=[1,2, \ldots, l] ; l$ is the number of fuzzy sets; $\mu_{i}$ is grade of membership. The control sketch is shown in Figure 4.

\section{Robotic Machining Simulation and Experiments}

4.1. Simulation. Before conducting machining experiments, simulations including open loop control, fuzzy-PID control, and fuzzy-sliding mode control are carried out to get a preview of the control scheme performance. The machining path for the simulation is shown in Figure 5, which can be classified as cut-into stage and stable machining stage. At cut-into stage, the cutter starts its path at position A and moves towards workpiece at the feed rate $V_{w}$ perpendicular to the workpiece. After reaching position $\mathrm{B}$, the cutter shifts its machining path which is parallel to the workpiece surface. The simulation parameters are original feed rate $V_{w}=$ $2 \mathrm{~mm} / \mathrm{s}$; machining depth $a_{p}=2 \mathrm{~mm}$; abrasive radius $R_{s}=$ $6 \mathrm{~mm}$; force target is $5 \mathrm{~N}$. 


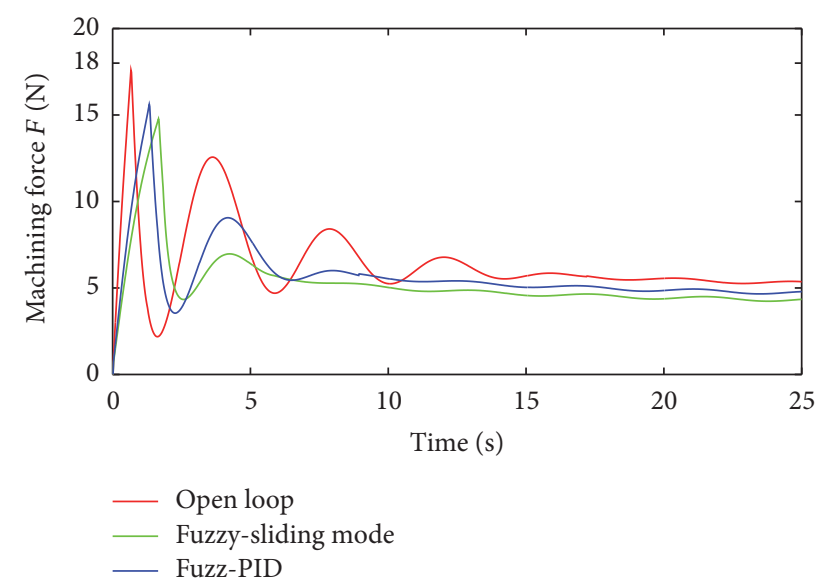

Figure 6: Control performance comparisons (fuzzy-PID, fuzzysliding mode, and open loop).

The simulation results are shown in Figure 6. According to (7) and (8), the deformation value in $x$ direction, named as $\sigma_{x}$, is impact by feed rate value $\left|V_{w}\right|$ and the angle $\theta$. When the machining path of cutter is perpendicular to the workpiece surface, the value of feed rate has a significant influence on the robotic deformation in $x$ direction. As shown in Figure 6, the peak value of machining force appears when the cutter reaches position $\mathrm{B}$. When no control is conducted on feed rate, the force peak value of open loop control is around $19 \mathrm{~N}$. The force peak values of fuzzy-PID and fuzzy-sliding mode control are around $15 \mathrm{~N}, 4 \mathrm{~N}$ lower than the one of open loop control, which is in compliance with (7). The machining force then decreases and oscillates for a while. The oscillation period of open loop control is around 14 seconds which is 5 seconds more than the one of fuzzy-PID control and almost 8 seconds more than the one of fuzzy-sliding mode control. Besides, the oscillation amplitude of fuzzy-sliding mode control is around $3 \mathrm{~N}, 2 \mathrm{~N}$ less than the one of fuzzyPID control. Therefore, compared with the other two control schemes, fuzzy-sliding mode control has the advantage in reducing the period and amplitude of oscillation and the peak value of machining force. The machining depth of the simulation is $2 \mathrm{~mm}$, which is similar to machining depth of rough machining process. And semifinishing and finishing machining process will be conducted after rough machining process. Considering the fact that the aim of proposed control scheme is to reduce the scale and time period of vibration and deformation, and the vibration and deformation could not be thoroughly eliminated, the time period of initial oscillation is acceptable.

Another simulation is performed to evaluate the impact of the gain coefficients $H_{c}$ and $H_{k}$ on the performance of control scheme. According to (9) and (11), the change of feed rate is influenced by $H_{c}$ and $H_{k}$, which can eventually affect the change of machining force. As shown in Figure 7, the peak value of machining force decreases from $11 \mathrm{~N}$ to $8 \mathrm{~N}$ as the value of $H_{k}$ increases from 0.1 to 1 . A reduction appears in the period and amplitude of oscillation when $H_{k}$ increases. However, while $H_{k}$ is larger than 0.5 , an obvious chatter shows

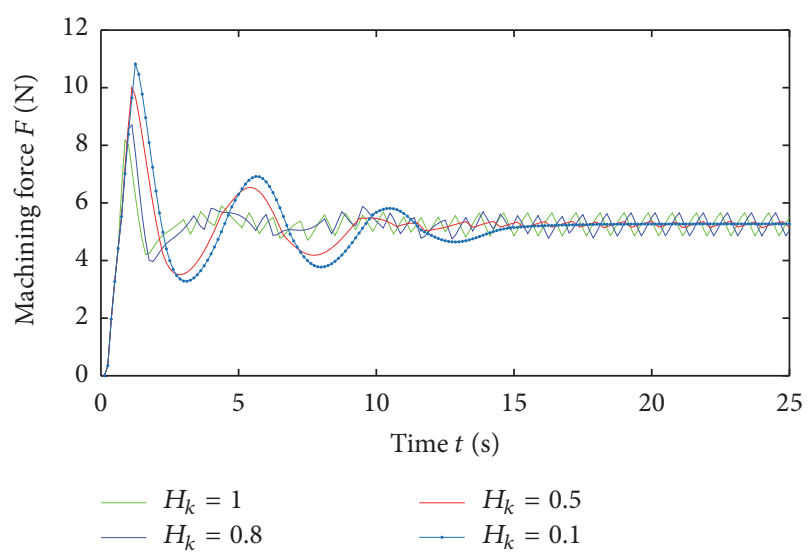

FIGURE 7: Impact of sliding mode control gain on cutting force.

up in stable machining stage, and the amplitude of it increases as the value of $H_{k}$ increases, which can be illustrated by (14). Similar performance appears in the evaluation of $H_{c}$.

Therefore, a preconclusion can be made that fuzzy-sliding mode control has the advantage in reducing the peak value of machining force, oscillation period, and amplitude. The modification of gain coefficients $H_{c}$ and $H_{k}$ can modify the rate of convergence. However, due to the influence of $H_{c}$ and $H_{k}$ on the chattering amplitude, the increase of both gain coefficients should be bounded.

\subsection{Machining Experiments Based on Fuzzy-Sliding Mode Control}

4.2.1. Robotic Machining System. The robotic machining system used for experiment is composed of Cartesian coordinate robot, expended rotating platform, force sensor, machining tool, and workpiece. As shown in Figure 8, the robot, consisting of Cartesian coordinate robot and expended rotating platform, has an open loop and serial structure, which is similar to general industrial robots. Therefore, it can completely illustrate the rigidity behavior of general industrial robots. The force sensor and machining tool are installed on the end of axis $Z$, while the workpiece is installed on the rotating platform.

4.2.2. Experiments. The experiments conducted on plane part of the workpiece and the parameters are shown in Figure 9. The machining path is the same as the one conducted in the simulations. The machining parameters are original feed rate $V_{w}=2 \mathrm{~mm} / \mathrm{s}$; machining depth $a_{p}=0.8 \mathrm{~mm}$; abrasive radius $R_{s}=6 \mathrm{~mm}$; abrasive width $L_{s}=5.5 \mathrm{~mm}$; rotational speed of cutter is $4000 \mathrm{r} / \mathrm{min}$. The aim of the machining force is $4 \mathrm{~N}$. Three kinds of measurement methods are used in this paper, including force sensor, three-coordinate measuring system, and roughness tester.

According to (6) and (7) and simulation (1), the machining force error is significantly impacted by the feed rate value $\left|V_{w}\right|$ while the machining path is perpendicular to the workpiece surface. As shown in Figure 10, a considerable increase in machining force appears in cut-in stage and 


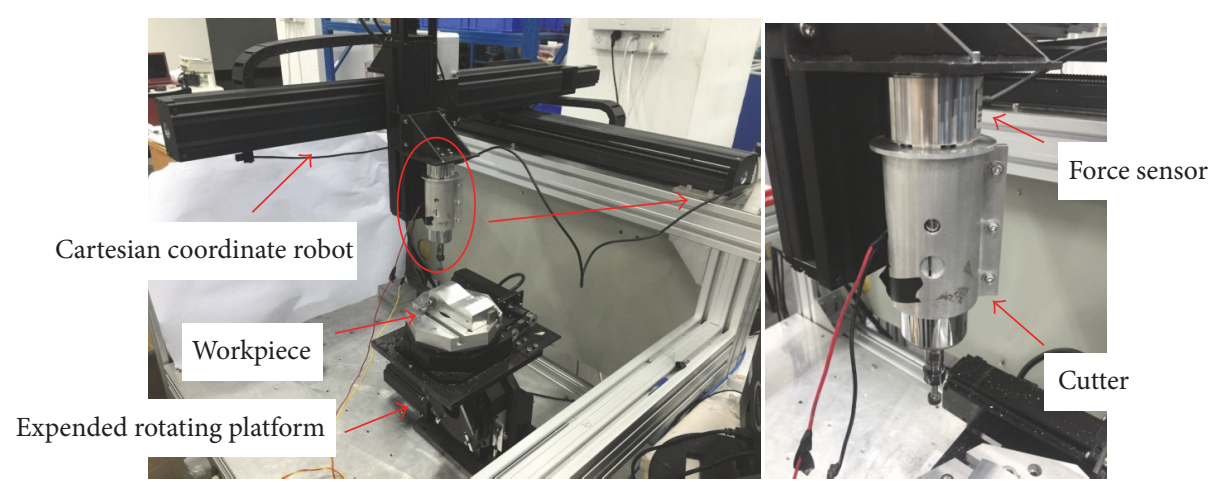

FIGURE 8: Architecture of robotic cutting system ((1) XYZ Cartesian coordinate robot; (2) rotating platform; (3) six-axis force sensor; (4) cutting tool; (5) workpiece).

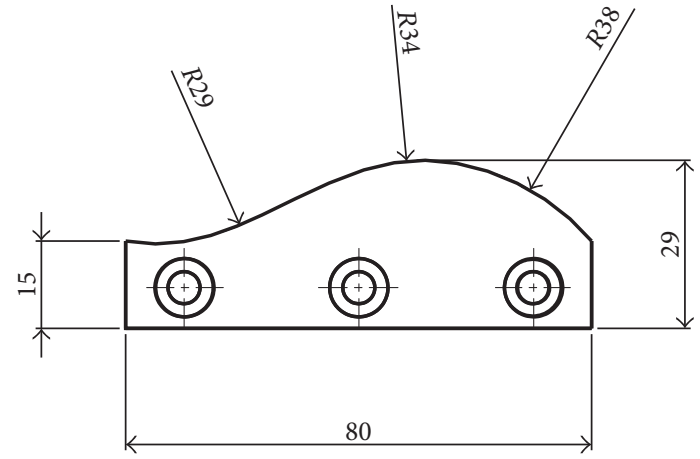

FIGURE 9: Workpiece (aluminum alloy).

reaches the peak value of $17 \mathrm{~N}$ at the 3 rd second. After that the machining force decreases and oscillates with amplitude of $7 \mathrm{~N}$ which is caused by the release of deformation. The stable machining stage start at 9 th second and the fluctuation of chatter is around $5 \mathrm{~N}$, while the average force is $4.5 \mathrm{~N}$. The machining force value at cut-in stage is higher than the one at stable machining stage which implies that the change of machining angle has a significant influence on the change of machining force in $x$ direction. This performance is in compliance with (5) and (6). The dimensional inspections are conducted on a three-coordinate measuring system (Global advantage 05.07.05). The actual machining depth is around $0.75 \mathrm{~mm}$, and the amplitude of fluctuation is around $0.06 \mathrm{~mm}$. The roughness of machining surface is $\mathrm{Ra} 1.821 \mu \mathrm{m}$.

The experiment result under fuzzy-PID control is shown in Figure 11. According to (5) and (6), the modification of feed rate $\left|V_{w}\right|$ can change the machining force value. Therefore the peak value is around $14 \mathrm{~N}, 3 \mathrm{~N}$ less than the one of open loop control. The machining force oscillates with amplitude of $6 \mathrm{~N}$ and achieves stable machining at 7 th second, 2 seconds less than one of open loop control. The fluctuation of chatter is around $3 \mathrm{~N}$ which is more smooth than the one of open loop control, and the average force is $4 \mathrm{~N}$. The actual machining depth is around $0.75 \mathrm{~mm}$ and the amplitude of fluctuation is around $0.04 \mathrm{~mm}$. The roughness of machining surface is $\mathrm{Ra}$ $1.432 \mu \mathrm{m}$.
According to (5) and (6), the modification of feed rate $\left|V_{w}\right|$ can change the machining force value. Therefore, the experiment uses fuzzy-sliding mode control to modify the feed rate according to the real-time status of system in order to smooth the fluctuation. The experiment result under fuzzysliding mode control is shown in Figure 12. The peak value is around $14 \mathrm{~N}$, which is almost the same as the one of fuzzy-PID control. The machining force oscillates with amplitude of $2 \mathrm{~N}$, less than the ones of other two control schemes, and achieves stable machining at 5 th second. Compared with fuzzy-PID control, fuzzy-sliding mode control achieves a reduction of 2 seconds in oscillation period and a reduction of $4 \mathrm{~N}$ in oscillation amplitude. The chatter amplitude decreases from $3 \mathrm{~N}$ to $2 \mathrm{~N}$. The reductions in the amplitude and period of oscillation result in a smoother force curve which implies verifying the validity of (8) and (10), indicating that a smooth force fluctuation can be achieved with the use of fuzzysliding control scheme. The actual machining depth is around $0.75 \mathrm{~mm}$ and the amplitude of fluctuation is around $0.03 \mathrm{~mm}$. The roughness of machining surface is $\mathrm{Ra} 1.292 \mu \mathrm{m}$.

\section{Conclusion}

With an open loop and serial structure, the stiffness of robot is low and easily results in deformation and vibration during machining process. The generation of deformation and the robotic machining mechanism are explored in this study to construct the dynamic model. Due to the complexity of robotic machining, simple control scheme is not sufficient enough to manage the force fluctuation that occurs during machining. With the view of this, a sliding mode control scheme based on fuzzy rule is proposed to reduce the peak value of machining force, the oscillation amplitude and period, and the amplitude of chatter. The simulations and relevant experiments are then conducted to evaluate the performance of fuzzy-sliding mode control. The results show that fuzzy-sliding mode control has the advantages in reducing the oscillation period and amplitude compared with fuzzy-PID control, making the reductions of $4 \mathrm{~N}$ and 2 seconds. The force peak values of fuzzy-PID control and fuzzy-sliding mode control are lower than the one of open loop control, achieving a reduction of $4 \mathrm{~N}$. 

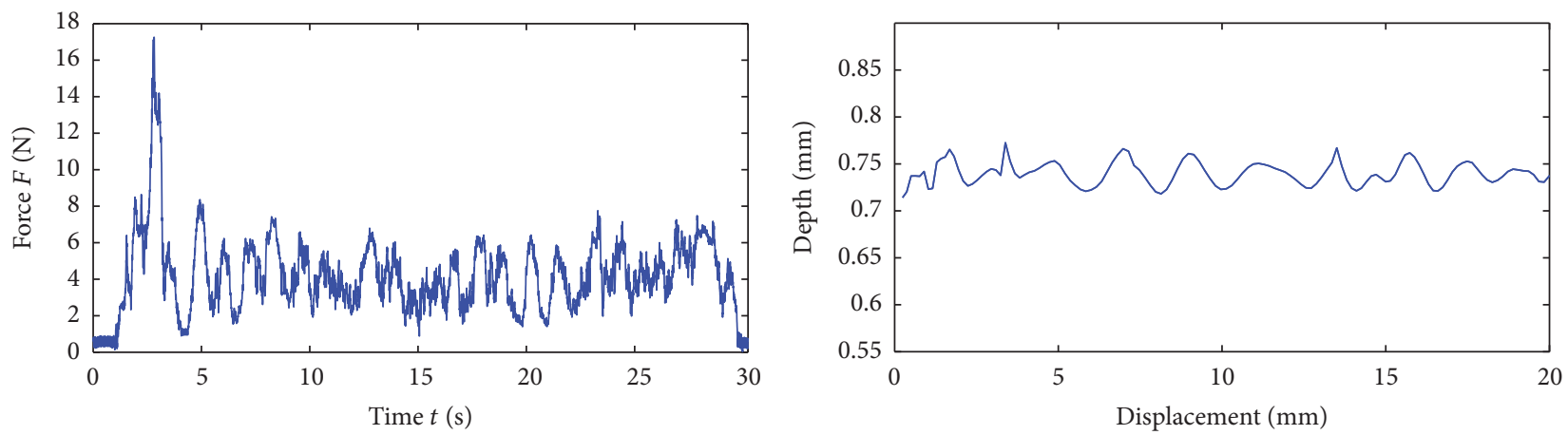

FIGURE 10: Experiment result of robotic machining under open loop control.
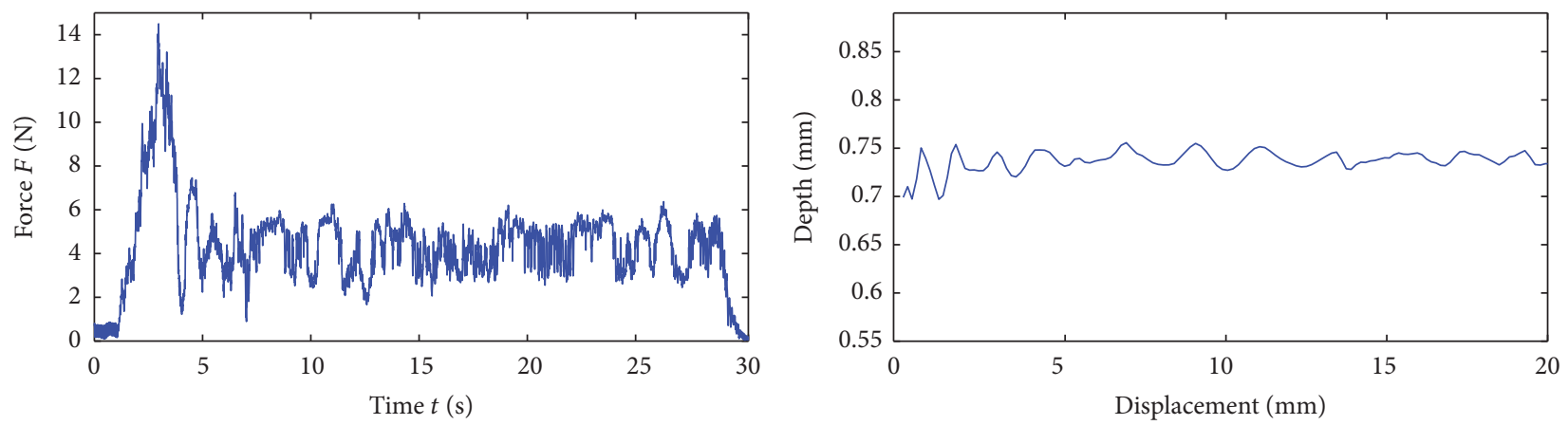

FIGURE 11: Experiment result of robotic machining under fuzzy-PID control.
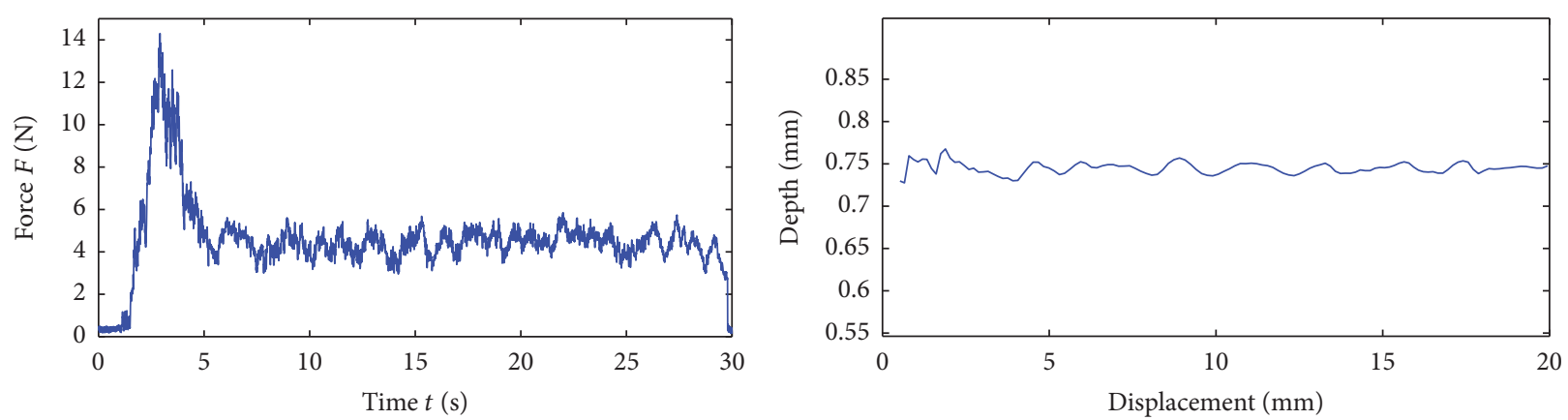

FIGURE 12: Experiment result of robotic machining under fuzzy-sliding mode control.

Current studies are mostly focused on system integration and force control, yet few of them concentrated on feed rate control. This study fills the gap in this field and provides a reference to later research.

\section{Conflicts of Interest}

The authors declare that they have no conflicts of interest.

\section{Acknowledgments}

This project is sponsored by National Science and Technology Major Project of China (no. 20152X04005006),
Science and Technology Planning Project of Guangdong Province, China (nos. 2014B090921004, 2014B090920001, and 2015B010918002), and Science and Technology Major Project of Guangzhou, China (no. 201505031617224).

\section{References}

[1] Y. Chen and F. Dong, "Robot machining: recent development and future research issues," International Journal of Advanced Manufacturing Technology, vol. 66, no. 9-12, pp. 1489-1497, 2013.

[2] L. Ding, H. Wu, Y. Yao, and Y. Yang, "Dynamic model identification for 6-DOF industrial robots," Journal of Robotics, vol. 2015, Article ID 471478, pp. 1-9, 2015. 
[3] A. Olabi, R. Béarée, O. Gibaru, and M. Damak, "Feedrate planning for machining with industrial six-axis robots," Control Engineering Practice, vol. 18, no. 5, pp. 471-482, 2010.

[4] F. Domroes and C. Krewet, "Application and analysis of force control strategies to deburring and grinding," Modern Mechanical Engineering, vol. 3, no. 2, pp. 11-18, 2013.

[5] Y. Karayiannidis and Z. Doulgeri, "Adaptive control of robot contact tasks with on-line learning of planar surfaces," Automatica, vol. 45, no. 10, pp. 2374-2382, 2009.

[6] K. Kiguchi and T. Fukuda, "Intelligent position/force controller for industrial robot manipulators-application of fuzzy neural networks," IEEE Transactions on Industrial Electronics, vol. 44, no. 6, pp. 753-761, 1997.

[7] M. Žarko and D. Vlastimir, "Hybrid industrial robot compliant motion control," Facta Universitatis. Series Automatic Control and Robotics, vol. 7, no. 1, pp. 99-110, 2008.

[8] S.-I. Matsuoka, K. Shimizu, N. Yamazaki, and Y. Oki, "Highspeed end milling of an articulated robot and its characteristics," Journal of Materials Processing Technology, vol. 95, no. 1-3, pp. 83-89, 1999.

[9] E. Abele, M. Weigold, and S. Rothenbücher, "Modeling and identification of an industrial robot for machining applications," CIRP Annals - Manufacturing Technology, vol. 56, no. 1, pp. 387390, 2007.

[10] H. Zhang, J. Wang, G. Zhang et al., "Machining with flexible manipulator: toward improving robotic machining performance," in Proceeding of the International Conference on Advanced Intelligent Mechatronics, pp. 1127-1132, Calif, USA, 2005.

[11] J. Wang, H. Zhang, and T. Fuhlbrigge, "Improving machining accuracy with robot deformation compensation," in Proceedings of the IEEE/RSJ International Conference on Intelligent Robots and Systems (IROS '09), pp. 3826-3831, October 2009.

[12] Y. Bai, N. Guo, and G. Agbegha, "Fuzzy interpolation and other interpolation methods used in robot calibrations," Journal of Robotics, vol. 2012, no. 2, Article ID 376293, pp. 69-74, 2012. 


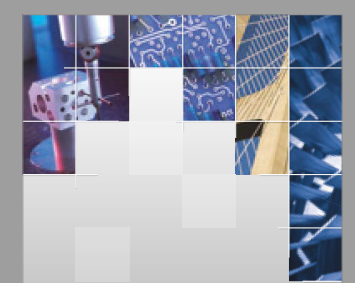

\section{Enfincering}
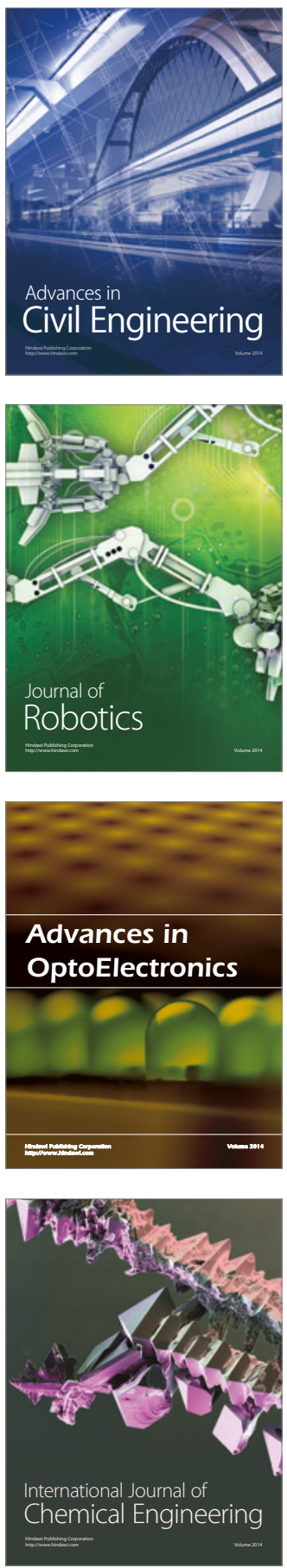

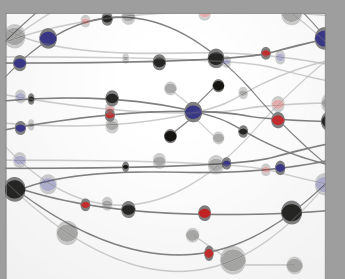

The Scientific World Journal

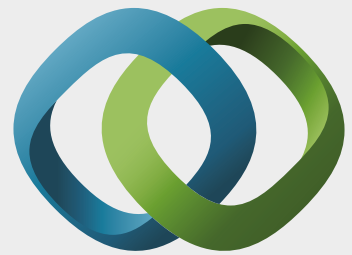

\section{Hindawi}

Submit your manuscripts at

https://www.hindawi.com
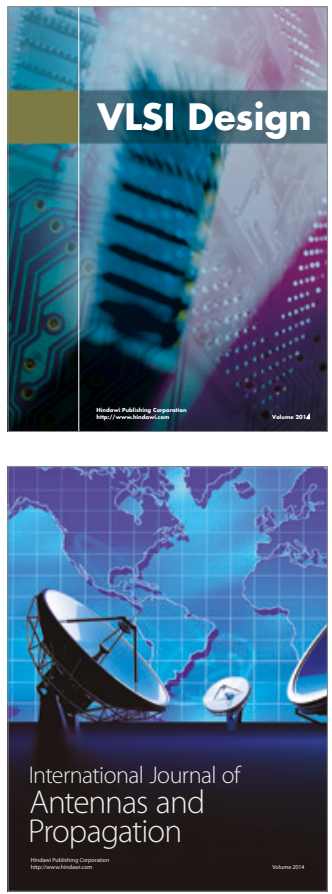

\section{Rotating}

Machinery
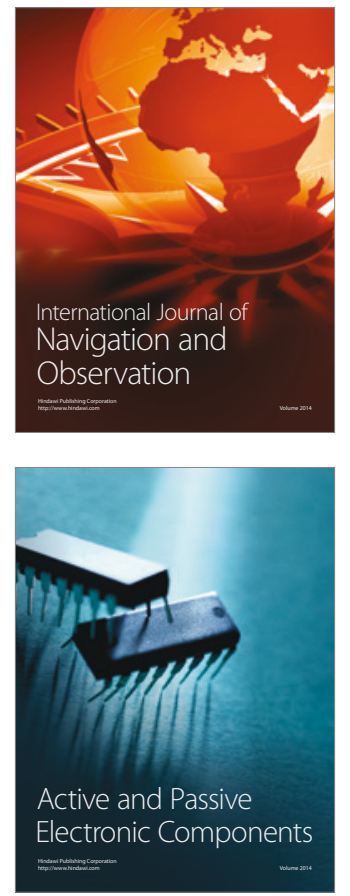
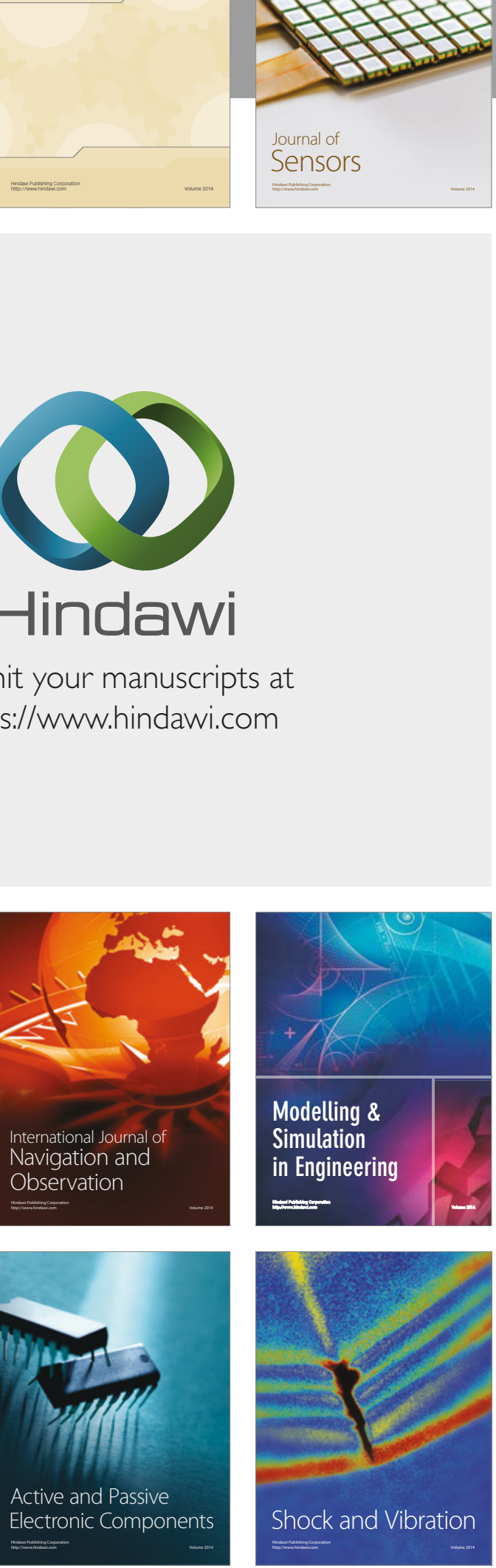
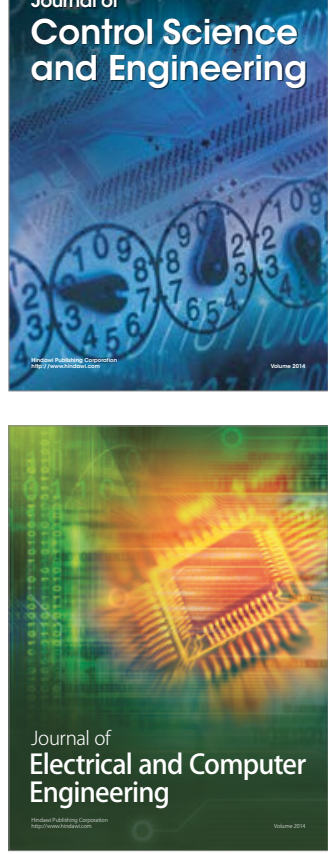

Distributed

Journal of

Control Science

and Engineering
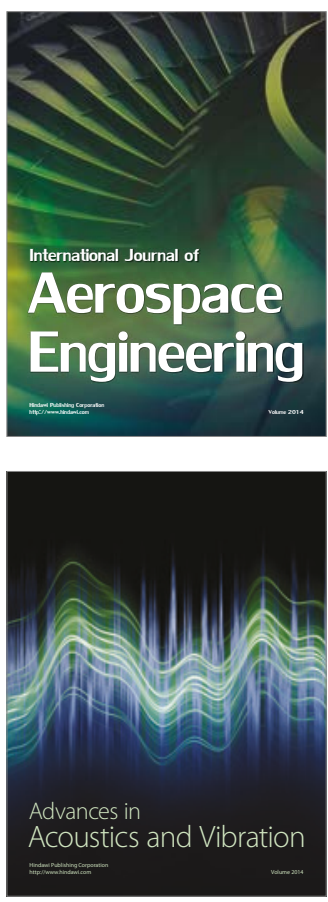

Sensor Networks 